\title{
Estimating the cost-effectiveness of pneumococcal conjugate vaccination in Brazil
}

\author{
Glaucia Vespa, ${ }^{1}$ Dagna O. Constenla, ${ }^{2}$ Camila Pepe, ${ }^{3}$ \\ Marco Aurélio Safadi, ${ }^{4}$ Eitan Berezin, ${ }^{4}$ José Cássio de Moraes, ${ }^{5}$ \\ Carlos Alberto Herrerias de Campos, ${ }^{6}$ Denizar Vianna Araujo, ${ }^{3}$ \\ and Ana Lucia S. S. de Andrade ${ }^{7}$
}

Suggested citation Vespa G, Constenla DO, Pepe C, Safadi MA, Berezin E, Moraes JC, et al. Estimating the cost-effectiveness of pneumococcal conjugate vaccination in Brazil. Rev Panam Salud Publica. 2009;26(6):518-28.

\begin{abstract}
Objective. To compare the costs and benefits of pneumococcal conjugate vaccination compared with no vaccination from the perspectives of the health care system and society.

Methods. Using data from established sources, we estimated the incidence and mortality due to invasive pneumococcal disease, pneumonia, and acute otitis media (AOM) for a hypothetical birth cohort of children from birth to 5 years.

Results. A universal pneumococcal conjugate vaccination program was estimated capable of annually avoiding 1047 cases of invasive disease, 58226 cases of pneumonia, and 209862 cases of AOM. When herd immunity effects were considered, the program prevented 1.3 million cases of pneumococcal disease and over 7000 pneumococcal deaths. At a vaccination cost of $R$ \$ 51.12 (US\$26.35) per dose, vaccination would cost annually $R \$ 4289$ (US\$2,211) per disability-adjusted life years averted. This does not take into account herd immunity effects.

Conclusions. At the current vaccine price, conjugate vaccination could be a cost-effective investment compared to other options to control childhood diseases. Further analysis is required to determine whether vaccination at the current price is affordable to Brazil.
\end{abstract}

Key words Streptococcus pneumoniae; pneumococcal infections; pneumococcal vaccines; cost efficiency analysis; Brazil.

Universidade Federal de São Paulo, Escola Paulista de Medicina, São Paulo (SP), Brazil.

2 Medical Technology Assessment, Fort Collins (CO), USA. Correspondence: Chaussee de Bruxelles 111A, 1410 Waterloo, Belgium. Phone/ fax: +32-2-351.5421; e-mail: dagnaconstenla@ yahoo.com

3 Universidade Estadual do Rio de Janeiro (UERJ), Departamento de Medicina Interna, Rio de Janeiro (RJ), Brazil.

4 Santa Casa de São Paulo, Faculdade de Ciências Médicas, Departamento de Pediatria, São Paulo (SP), Brazil.

5 Santa Casa de São Paulo, Faculdade de Ciências Médicas, Departamento de Medicina Social, São Paulo (SP), Brazil.

6 Santa Casa de São Paulo, Faculdade de Ciências Médicas, Departamento de Otorrinolaringologia, São Paulo (SP), Brazil.
Streptococcus pneumoniae (S. pneumoniae) has been recognized as the leading cause of invasive bacterial disease, pneumonia, and acute otitis media (AOM), affecting infants and young children at an age when they are most vulnerable. Globally, S. pneumoniae is estimated to cause between 700000 to 1 million annual deaths (1).

Due to the public health impact associated with such diseases and the safety

7 Departamento de Saúde Coletiva, Universidade Federal de Goiás, Goiânia (GO), Brazil. and effectiveness profile of the heptavalent pneumococcal conjugate vaccine (2-5), the World Health Organization (WHO) considers the introduction of this vaccine in national immunization programs as a public health priority (6). This recommendation is in accordance with the fourth millennium goal of the United Nations Development Program (UNDP) to reduce childhood mortality by twothirds by 2015 (7). To date, the heptavalent pneumococcal conjugate vaccine has been included in the national immunization programs of 16 countries (Australia, 
Belgium, Canada, France, Germany, Greece, Holland, Italy, Kuwait, Luxemburg, Mexico, Norway, Qatar, Switzerland, United Kingdom, and the United States). Additional countries planned to incorporate the vaccine in 2008, including the United Arab Emirates, Austria, Cyprus, Denmark, Peru, and Spain. The number of countries including this vaccine in their immunization schedule is changing rapidly. By the time of publication, this number will likely be dated. In Latin America, Brazil, Chile, and Colombia have targeted immunization programs in place. If widely adopted in the developing world, the vaccine may significantly reduce the incidence of invasive pneumococcal disease, pneumonia, AOM, and drug-resistant strains and consequently the burden of pneumococcal infection on families and society.

Public health policy makers increasingly consider cost-effectiveness, as well as clinical effectiveness, when evaluating the introduction of new vaccines. Various studies evaluating the pneumococcal conjugate vaccine in America, Australia, Europe and the developing world (8-20) suggest that it may be a costeffective strategy for reducing the health and economic burden of pneumococcal disease.

The present paper evaluates the costs and benefits of a national heptavalent pneumococcal conjugate vaccination program using country-specific model inputs. Our main objective was to assess the cost-effectiveness of pneumococcal conjugate vaccination, compared with no vaccination, from the perspectives of the health care system and society.

\section{MATERIALS AND METHODS}

\section{Analytic overview}

We developed an Excel-based decision analysis model to estimate the health and economic burden of pneumococcal disease in Brazil, and to determine the cost-effectiveness of the heptavalent pneumococcal conjugate vaccine, compared to no vaccination. The model estimates the expected health outcomes and costs associated with pneumococcal disease in a hypothetical birth cohort of children in Brazil between birth and age 5 years. It also estimates the disease burden and total costs that may be averted with vaccination. The principal inputs to the model include epidemiological infor- mation on disease incidence, health care costs associated with different types of pneumococcal cases, and the effectiveness and costs of vaccination. Model outcomes include cases of pneumococcal disease averted, lives saved, disabilityadjusted life years (DALYs) averted, and costs. These outcomes were evaluated at country level, using country-specific model inputs. The analytic horizon, or the period over which the costs and benefits of vaccine introduction were evaluated (time span), was 10 years.

We adopted the perspectives of the health care system and society. Direct medical costs included the costs of laboratory tests and other procedures, medication, supplies, facilities and personnel needed for treatment. Non-medical direct costs included the transportation to and from the medical facility, childcare, home care, time waiting for care and time undergoing care. Indirect cost estimates were based on caregiver productivity losses that may occur due to illness or death. All estimates were based on the expected events and costs for children below 5 years of age considering an an-

FIGURE 1. Decision tree depicting the two policy options (vaccine introduction in Brazil vs. no vaccine) and subsequent events that may be experienced by each child in Brazil

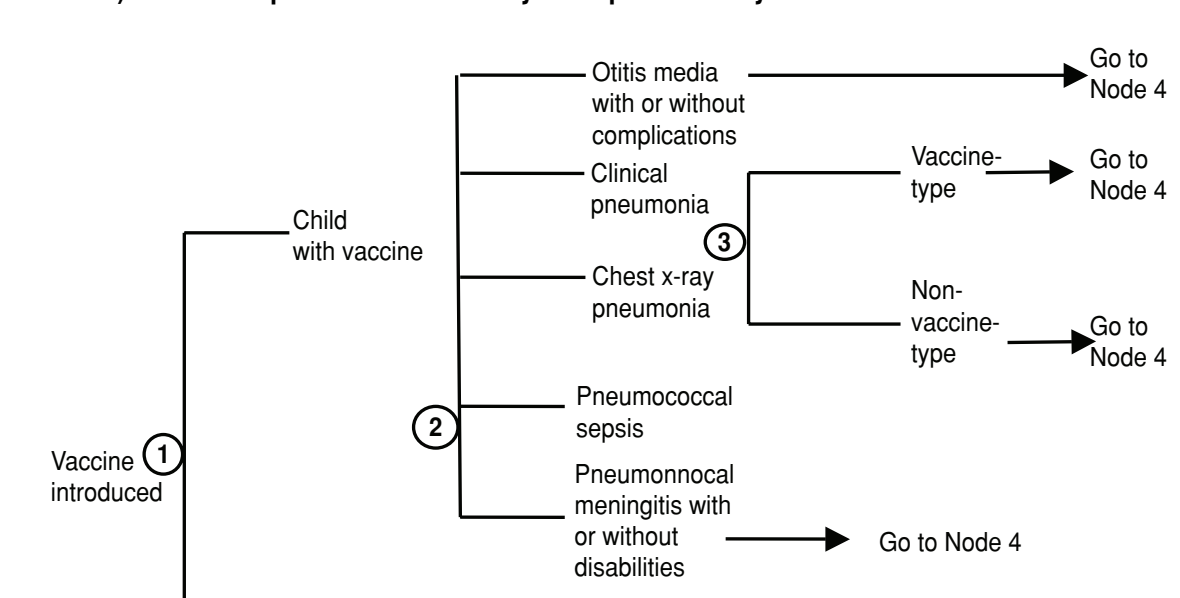

Child without vaccine nual birth cohort of 3469937 (21). Estimates are expressed in 2006 US dollars and Brazilian reals $(\mathrm{R} \$)$, and all future costs and DALY estimates were discounted at a rate of $3 \%$, as recommended by the U.S. Panel on Cost-Effectiveness in Health and Medicine (22) and the World Bank Global Burden of Disease (GBD) project (23).

\section{Model structure}

The model structure is described in Figure 1. In brief, the root of the decision tree is a decision node with two branches representing the two alternatives of vaccination and no vaccination. Each path through the decision tree represents a possible sequence of chance and decision events. This sequence of events is associated with a consequence, which is valued in terms of DALYs averted, cases prevented, or lives saved. A probability is assigned to each chance of event in the model. This probability is estimated from data in clinical studies, national and institutional statistics, and other secondary sources.

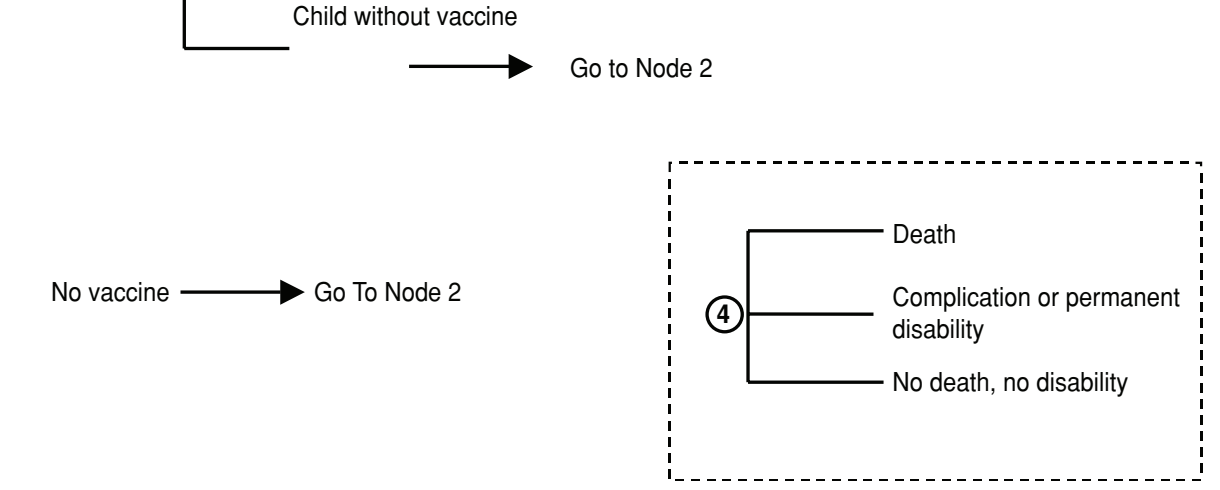




\section{Probabilities}

Disease burden was estimated as the number of disease cases and deaths based on the size of the 2006 under 5 cohort (3 469 937) (21), cumulative incidences of disease and case fatality ratios (CFRs) (2426), and the estimated age distributions of each event (27). The following diseases were included: all-cause AOM, all-cause clinical pneumonia (inpatient/outpatient), all-cause chest x-ray-confirmed pneumonia (inpatient/outpatient), pneumococcal sepsis, and pneumococcal meningitis. Overall, bacteremia, non-sepsis, non-meningitis invasive pneumococcal disease burden was not estimated in the current analysis.

The model directly estimated the number of cases of averted AOM due to any cause, averted clinical pneumonia due to any cause, and averted chest $\mathrm{x}$-rayconfirmed pneumonia due to any cause. We used algebraic rearrangements to estimate the proportion of AOM, clinical pneumonia and chest $x$-ray-confirmed pneumonia (due to any cause) attributed to pneumococcus as follows:

- averted otitis media cases $=$ (no. pneumococcal otitis media cases $) \times(\%$ pneumococci that are vaccine type) $\times$ (\% children receiving vaccine) $\times$ (vaccine efficacy);

- averted clinical pneumonia cases = (no. pneumococcal clinical pneumonia cases $) \times(\%$ pneumococci that are vaccine type $) \times(\%$ children receiving vaccine $) \times($ vaccine efficacy $)$;

- averted chest $x$-ray + pneumonia cases $=$ (no. chest $x$-ray + pneumonia cases) $\times$ (\% pneumococci that are vaccine type) $x$ $(\%$ children receiving vaccine $) \times($ vaccine efficacy).

Age-specific annual incidences were used to develop cumulative incidence estimates (ages 0 to 5) using standard Kaplan-Meier analysis (28). Age distribution of disease was based on results from a survey of eight health care providers conducted in Goiás, Brazil. The details of this survey's methods and results have been described elsewhere $(24,27,29)$. The proportion of clinical pneumonia cases that are hospitalized was based on Brazilian estimates of the proportion of severe acute lower respiratory infections in children following a recently proposed methodology (30) and on a panel of three local physicians.
Table 1 provides a summary of the disease risk estimates used in the base case analysis model (21, 22, 24-26, 31-33).

\section{Vaccination coverage, efficacy and costs}

A three-dose administration schedule was assumed for pneumococcal conjugate vaccine, as recommended for diphtheria-tetanus-pertussis (DTP3)-containing vaccines in Pan-American Health Organization (PAHO) member states (2, 4 , and 12 months of age). However, a four-dose schedule was also considered in the analysis. For the base case analysis, it was assumed that the expected pneumococcal vaccination coverage with the proposed $2+1$ scheme in Brazil is $96 \%$. This would be equal to the Brazilian average proportion of children reported to receive three doses of DTP3 vaccine in 2006 (DTP3 rate) (34).

Estimates of pneumococcal conjugate vaccine efficacy were available from several large, randomized controlled trials. However, because no trial results were available from a Brazilian setting, we used vaccine efficacy estimates for otitis media, clinical pneumonia, and invasive pneumococcal disease from the trial conducted in Northern California by Kaiser Permanente (2-4). The vaccine efficacy estimate for chest $x$-ray confirmed pneumonia was based on a later re-analysis of the original trial's results (5). To extrapolate trial results to Brazil, we adjusted vaccine efficacy by the ratio of the Brazilian estimate for vaccine-type serotype coverage (31) and the trial vaccine serotype cover- age $(3,4)$. The vaccine serotype coverage for the heptavalent pneumococcal conjugate vaccine in Brazil is lower $(70 \%)$ than that reported in the clinical trials $(80 \%)$, since serotypes 1 and 5 are prevalent in invasive pneumococcal disease in children. Currently, no efficacy estimates exist for a $2+1$ schedule and the evidence of effectiveness from real life experiments is just starting to appear. This is a crucial study limitation that needs to be considered when interpreting the study findings. We assumed that vaccine would prevent cases of disease and deaths between ages 0 and 5 years only.

The costs of vaccination include the cost of administration, the price of each dose, the number of doses given (based on coverage level), and expected losses from waste. The price at which vaccine will be made available to Brazil is unknown. Our base case used R\$ 51.12 (US\$ 26.35) per vaccine dose (US\$ $1.00=$ $\mathrm{R} \$ 1.9399$ ) (35), according to the price at which a dose of vaccine was purchased by the PAHO Revolving Fund for Vaccine Procurement at the time of this study. Incremental vaccine administration costs (cold chain, transport, personnel, injection supplies, training, other) and a $10 \%$ wastage rate assumed were based on expert opinion (personal communication, Dr. H Sato, Secretaria de Estado da Saúde de São Paulo, May 2007).

\section{Costs}

The base case analysis was performed from a societal perspective, where all direct medical and non-medical costs

TABLE 1. Summary of disease risk estimates used in the base case analysis

\begin{tabular}{|c|c|c|c|c|}
\hline \multirow[b]{2}{*}{ Model Input } & \multirow[b]{2}{*}{$\begin{array}{c}\text { Base case } \\
\text { estimate }\end{array}$} & \multicolumn{2}{|c|}{ Plausible range } & \multirow[b]{2}{*}{$\begin{array}{c}\text { Source } \\
\text { (reference) }\end{array}$} \\
\hline & & $\begin{array}{c}\text { Lower } \\
\text { limit }\end{array}$ & $\begin{array}{c}\text { Upper } \\
\text { limit }\end{array}$ & \\
\hline \multicolumn{5}{|l|}{ General } \\
\hline Birth cohort & 3469937 & - & - & $(21)$ \\
\hline Life expectancy & 71.74 & - & - & (32) \\
\hline Discount rate & $3 \%$ & $3 \%$ & $7 \%$ & (22) \\
\hline \multicolumn{5}{|c|}{ Disease-related inputs-probability of: } \\
\hline Acute otitis media & 0.900 & 0.70 & 1.10 & $(25)$ \\
\hline Clinical pneumonia & 0.0911 & 0.0683 & 0.1138 & $(24,33)$ \\
\hline Chest x-ray + pneumonia & 0.0566 & 0.0435 & 0.0714 & $(24,33)$ \\
\hline Pneumococcal sepsis & 0.0001 & 0.00008 & 0.00013 & (33) \\
\hline Pneumococcal meningitis & 0.000356 & 0.000138 & 0.000428 & $(26)$ \\
\hline \multicolumn{5}{|l|}{ Case fatality rates for: } \\
\hline Clinical pneumonia & $3 \%$ & $1.9 \%$ & $5.5 \%$ & $(32,33)$ \\
\hline Chest x-ray + pneumonia & $5.4 \%$ & $5.1 \%$ & $5.8 \%$ & $(32,33)$ \\
\hline Pneumococcal sepsis & $35 \%$ & $27 \%$ & $44 \%$ & $(32,33)$ \\
\hline Pneumococcal meningitis & $37 \%$ & $22 \%$ & $50 \%$ & $(32,33)$ \\
\hline Probability vaccine serotype & $70 \%$ & $60 \%$ & $87 \%$ & $(31)$ \\
\hline
\end{tabular}


borne by governments and families were considered. Direct medical costs (or the cost of treatment) included hospital days, medical personnel time, diagnostic tests, and medications. These costs were derived from detailed interviews conducted regarding resource utilization with 16 physicians in Brazil. Two otolaryngologists and four speech therapists answered questions about cochlear implants and treatment of AOM; 10 additional physicians answered questions about the treatment of meningitis, pneumonia and sepsis. These physicians came from Santa Casa de Misericórdia de São Paulo, Hospital de Reabilitação de Anomalias Craniofaciais/Universidade Federal de São Paulo (HRAC/ UNIFESP), Campus Botucatu, and from a network of seven pediatric hospitals in Goiânia (24, 29) (Hospital de Doenças Tropicais, Hospital Materno-Infantil, Instituto Goiano de Pediatria-Igope, Pronto Socorro Infantil de Goiânia, Hospital Menino Jesus, Hospital da Criança, Hospital Santa Bárbara), as part of a major investigation of childhood community-acquired pneumonia approved by the appropriate ethics committees. The interview data on resource utilization were combined with unit cost data to estimate total direct medical cost per case of disease. Unit cost data were based on hospital charge data (Sistema de Informação Hospitalar-SIH/SUS), and outpatient charge data (Sistema de Informações Ambulatoriais-SIA/SUS). This charge data are provided by DATASUS, a core information system that is maintained by the Brazilian federal government. DATASUS contains data on amounts that the government pays to hospitals for every approved health service provided (36).

In addition to treatment costs, transportation costs to health care facilities were also included in the calculations. For the base case analysis, these costs were based on assumptions made about the number of trips to and from the doctor's office and/or clinic and the cost of each trip. The number of trips to and from the doctor's office and/or clinic was based on the number of outpatient visits and hospital admissions reported by a panel of four physicians and three speech therapists in São Paulo. The cost of each trip was derived from the National Association of Urban Transportation Services (Associação Nacional das Empresas de Transportes Urbanos) (37).
Indirect costs associated with lost time from paid work were calculated for the caregivers of all patients. For the base case analysis, these costs were based on the number of days off work (one outpatient consultation or 1 day in the hospital was assumed to be the same as 1 day off work), assuming 22 days of work and an average minimum monthly salary in Brazil of $R \$ 337.50$. This average minimum monthly salary is based on the latter part of 2006 (April-December) (38).

Additional costs included in the cost calculation were government benefits. The Brazilian government generally provides patients with disabilities a lifetime pension from the time they become disabled (39). This lifetime pension was added to the cost of patients whose meningitis resulted in deafness or neuromotor disabilities.

Secondary analyses were performed using three additional scenarios. These scenarios reflect changes made to the cost estimates based on alternative cost sources. Scenario 1 includes cost estimates based on the World Health Organization-Choosing Interventions that are Cost Effective (WHO-CHOICE) project (40). Scenario 2 includes cost estimates based on data from Brazilian health maintenance organizations (HMOs) and managed care organizations (MCOs) that are part of the Brazilian Medical Association (Associação Médica Brasileira, AMB) (41).

Scenario 3 includes cost estimates based on the public (SIH/SUS; SIA/ SUS) and private (HMO/MCO) sectors $(36,41)$. This scenario assumes that $80 \%$ of the costs are from the public sector and $20 \%$ are from the private sector (42). The costs derived from these various sources were combined with resource utilization data based on expert interviews conducted in 2001 and 2006 (27).

The WHO-CHOICE project provides estimates of the per diem cost of hospitals, outpatient visits, and health center visits for 14 epidemiological categories based on geographical region and mortality stratum. The hospital and outpatient unit cost data are specific to public hospitals and assume an $80 \%$ occupancy rate. The per diem/visit cost estimate includes such items as the cost of the facility, personnel, equipment, and food and excludes items such as medications and diagnostic tests. The per diem cost of a hospital bed day and outpatient visit are divided into three levels of care (pri- mary, secondary, tertiary) because unit costs generally increase by increasing level of care. Since the proportion of inpatients and outpatients who visit each of the three hospital levels in Brazil is unknown, the proportions were estimated based on physician interviews (27).

Unit cost data from the private sector are part of the data core system maintained by the federal government and reflects charge data from HMOs and MCOs.

Table 2 provides a summary of selected model inputs, including cost estimates, for the base case analysis model $(2-5,27,37,38,43-46)$.

\section{Health outcomes}

The base case analysis considered annual cases of disease and deaths averted by vaccination. Cases and deaths averted were converted into years of life lost and years of life lived with disability and then were aggregated into DALYs. We used standard methods and assumptions, including age weighting, discounting, and disability weights, in estimating DALYs $(23,47)$. DALYs averted were based on Brazil's average life expectancy at birth, derived from DATASUS (48).

\section{Cost-effectiveness analysis}

Incremental cost-effectiveness ratios (ICERs) compare the difference in cost with and without pneumococcal conjugate vaccination over the difference in health outcome with and without pneumococcal conjugate vaccination. For the cost-effectiveness analyses, the medical costs averted by vaccination were subtracted from the costs invested in vaccination and then divided by the health outcome. The relationship between cost and health outcome is described as follows: ICER $=$ (vaccine-related costs cost of cases of disease averted)/(DALYs averted). The ICER numerator and denominator were calculated by multiplying probabilities in the decision tree by values for costs and DALYs, using standard decision analytic methods $(22,49)$.

Several standards can be used for determining whether an intervention is cost-effective (in terms of US\$/DALY averted). The appropriateness of the different approaches depends on the perspective of the decision-maker. We used the WHO's thresholds of cost-effective 
interventions defined as ICERs less than three times the gross domestic product (GDP) per capita and very cost-effective interventions defined as ICERs below the GDP per capita (50).

\section{Sensitivity analyses}

We performed univariate sensitivity analyses on certain model input parameters to explore the impact of uncertainties on our results. First, we explored the impact of varying the variables used to estimate pneumococcal disease incidence. Next, we varied all cost values over a wide range. In addition, we analyzed the impact of the results of modifying vaccination coverage, efficacy and costs. We also varied the discount rate between zero and $10 \%$. Last but not least, we incorporated herd protection effects using invasive pneumococcal disease incidence data of adults from the United States, since no Brazil-specific estimates are currently available. In the U.S., large herd immunity effects have been observed, with consequent large effects on the cost-effectiveness of vaccine.

Estimates of vaccine protection for nonvaccinated populations (herd immunity) were based on published estimates of invasive pneumococcal disease incidence and case fatality rates among U.S. adults. We then applied the proportion reductions in invasive pneumococcal disease seen among U.S. adults to the Brazilian incidence estimates in order to calculate cases and deaths averted due to herd immunity among older children, adolescents and adults. DALYs averted were based on the estimated median age at time of disease. Based on the U.S. study, the incidence of invasive pneumococcal disease among non-vaccinated children and adults was as follows: age 5 to $<15$ years $=5$ per 100000 ; age 15 to $<45$ years $=11$ per 100000 ; age 45 to $<65$ years $=21$ per 100000 ; age $\geq 65$ years $=60$ per 100000 . The case-fatality rate was $19.3 \%$ and the proportion of invasive pneumococcal disease averted due to herd immunity was $49 \%$. This varies by age.

\section{RESULTS}

\section{Health outcomes}

Table 3 provides annual projected health outcomes of pneumococcal vaccination in Brazil. Without a vaccination
TABLE 2. Selected model inputs for base case analysis

\begin{tabular}{|c|c|c|c|c|}
\hline \multirow[b]{2}{*}{ Model Input } & \multirow[b]{2}{*}{$\begin{array}{l}\text { Base case } \\
\text { estimate }\end{array}$} & \multicolumn{2}{|c|}{ Plausible range } & \multirow[b]{2}{*}{$\begin{array}{c}\text { Source } \\
\text { (reference) }\end{array}$} \\
\hline & & $\begin{array}{l}\text { Lower } \\
\text { limit }\end{array}$ & $\begin{array}{l}\text { Upper } \\
\text { limit }\end{array}$ & \\
\hline \multicolumn{5}{|l|}{ Health resource-related inputs-probability that: } \\
\hline Clinical pneumonia is hospitalized & 0.08 & - & - & $(27)$ \\
\hline Chest $\mathrm{x}$-ray + pneumonia is hospitalized & 0.92 & - & - & $(27)$ \\
\hline \multicolumn{5}{|l|}{$\begin{array}{l}\text { Disability and complication-related inputs- } \\
\text { probability of: }\end{array}$} \\
\hline Complication due to $\mathrm{AOM}^{\mathrm{a}}$ & 0.0001 & - & - & $(27)$ \\
\hline Deafness due to meningitis & 0.13 & - & - & (27) \\
\hline Neuromotor disorder due to meningitis & 0.17 & - & - & $(27)$ \\
\hline \multicolumn{5}{|l|}{ DALYs ${ }^{b}$} \\
\hline Acute otitis media & 0.0227397 & - & - & $(27)$ \\
\hline \multicolumn{5}{|l|}{ Clinical pneumonia } \\
\hline Inpatient & 0.0405479 & - & - & $(27)$ \\
\hline Outpatient & 0.0200000 & - & - & (27) \\
\hline \multicolumn{5}{|l|}{ Chest $x$-ray + pneumonia } \\
\hline Inpatient & 0.0452054 & - & - & $(27)$ \\
\hline Outpatient & 0.0287671 & - & - & (27) \\
\hline Pneumococcal sepsis & 0.0383561 & - & - & (27) \\
\hline Pneumococcal meningitis & 0.0410958 & - & - & (27) \\
\hline Vaccination coverage rate & $96 \%$ & $89 \%$ & $100 \%$ & $\begin{array}{l}\text { Author's } \\
\text { assumption }\end{array}$ \\
\hline \multicolumn{5}{|l|}{ Vaccine efficacy } \\
\hline Against acute otitis media & $7 \%$ & $4 \%$ & $20 \%$ & $(2-4)$ \\
\hline Against clinical pneumonia $^{c}$ & $3 \%$ & $0 \%$ & $9 \%$ & $(2-4)$ \\
\hline Against chest $x$-ray + pneumonia ${ }^{c}$ & $25.97 \%$ & $4 \%$ & $34 \%$ & (5) \\
\hline Against vaccine type IPD ${ }^{d}$ & $97 \%$ & $83 \%$ & $99.9 \%$ & $(2-4)$ \\
\hline Against tube placement & $17 \%$ & - & - & $(2-4)$ \\
\hline Against adenoidectomy ${ }^{e}$ & $17 \%$ & - & - & $(2-4)$ \\
\hline \multicolumn{5}{|l|}{ Herd immunity relative factor } \\
\hline Against vaccine type IPD ${ }^{d}$ & 0.49 & 0.00 & 0.49 & $(43)$ \\
\hline \multicolumn{5}{|l|}{ Vaccine program } \\
\hline Number of vaccine doses & 3 & 3 & 4 & Assumption \\
\hline Wastage rate & $10 \%$ & - & - & $\begin{array}{l}\text { Personal } \\
\text { communication }\end{array}$ \\
\hline \multicolumn{5}{|l|}{ Vaccine program costs } \\
\hline Vaccine program cost per dose & $\mathrm{R} \$ 0.00$ & $\mathrm{R} \$ 0.00$ & $\mathrm{R} \$ 1.00$ & $\begin{array}{l}\text { Personal } \\
\text { communication }\end{array}$ \\
\hline Vaccine cost per dose & $\mathrm{R} \$ 51.12$ & $\mathrm{R} \$ 48.50$ & $\mathrm{R} \$ 51.12$ & $\begin{array}{l}\text { Personal } \\
\text { communication }\end{array}$ \\
\hline \multicolumn{5}{|l|}{$\begin{array}{l}\text { Disease-related, cost per case, societal } \\
\text { perspective }^{f}(R \$ 2006)\end{array}$} \\
\hline \multicolumn{5}{|l|}{ Acute otitis media without complication } \\
\hline Treatment costs & 19.10 & - & - & $(44)$ \\
\hline Transport costs & 6.40 & - & - & (37) \\
\hline Caregiver time loss & 34.55 & - & - & (38) \\
\hline Government benefits & - & - & - & \\
\hline \multicolumn{5}{|l|}{ Acute otitis media with complication } \\
\hline Treatment costs & 85.39 & - & - & $(44,45)$ \\
\hline Transport costs & 8.02 & - & - & $(37)$ \\
\hline Caregiver time loss & 43.29 & - & - & (38) \\
\hline Government benefits & - & - & - & \\
\hline Clinical pneumonia, outpatient & & & & \\
\hline Treatment costs & 26.65 & - & - & $(44)$ \\
\hline Transport costs & 9.60 & - & - & (37) \\
\hline Caregiver time loss & 51.82 & - & - & (38) \\
\hline Government benefits & - & - & - & \\
\hline Clinical pneumonia, inpatient & & & & \\
\hline Treatment costs & 511.61 & - & - & $(45)$ \\
\hline Transport costs & 12.80 & - & - & (37) \\
\hline Caregiver time loss & 139.56 & - & - & (38) \\
\hline Government benefits & - & - & - & \\
\hline Chest x-ray + pneumonia, outpatient & & & & \\
\hline Treatment costs & 58.14 & - & - & $(44)$ \\
\hline Transport costs & 9.60 & - & - & (37) \\
\hline Caregiver time loss & 51.82 & - & - & (38) \\
\hline Government benefits & - & - & - & \\
\hline & & & & (Continues) \\
\hline
\end{tabular}


TABLE 2. (Continued)

\begin{tabular}{|c|c|c|c|c|}
\hline \multirow[b]{2}{*}{ Model Input } & \multirow[b]{2}{*}{$\begin{array}{l}\text { Base case } \\
\text { estimate }\end{array}$} & \multicolumn{2}{|c|}{ Plausible range } & \multirow[b]{2}{*}{$\begin{array}{c}\text { Source } \\
\text { (reference) }\end{array}$} \\
\hline & & $\begin{array}{l}\text { Lower } \\
\text { limit }\end{array}$ & $\begin{array}{l}\text { Upper } \\
\text { limit }\end{array}$ & \\
\hline \multicolumn{5}{|c|}{ Chest x-ray + pneumonia, inpatient } \\
\hline Treatment costs & 511.61 & - & - & $(45)$ \\
\hline Transport costs & 12.80 & - & - & (37) \\
\hline Caregiver time loss & 139.56 & - & - & (38) \\
\hline Government benefits & - & - & - & \\
\hline \multicolumn{5}{|l|}{ Pneumococcal sepsis } \\
\hline Treatment costs & 1718.65 & - & - & $(45)$ \\
\hline Transport costs & 3.20 & - & - & (37) \\
\hline Caregiver time loss & 241.82 & - & - & (38) \\
\hline Government benefits & - & - & - & \\
\hline \multicolumn{5}{|l|}{ Pneumococcal meningitis } \\
\hline Treatment costs & 982.79 & - & - & $(45)$ \\
\hline Transport costs & 3.20 & - & - & (37) \\
\hline Caregiver time loss & 186.55 & - & - & (38) \\
\hline Government benefits & - & - & - & \\
\hline \multicolumn{5}{|c|}{ Pneumococcal meningitis, with deafness } \\
\hline Treatment costs & 7189.93 & - & - & $(45,46)$ \\
\hline Transport costs & 9.60 & - & - & $(37)$ \\
\hline Caregiver time loss & 829.09 & - & - & (38) \\
\hline Government benefits & 688.50 & - & - & (46) \\
\hline \multicolumn{5}{|c|}{$\begin{array}{l}\text { Pneumococcal meningitis, with neuromotor } \\
\text { disabilities }\end{array}$} \\
\hline Treatment costs & 8052.96 & - & - & $(44,45)$ \\
\hline Transport costs & 3.20 & - & - & $(37)$ \\
\hline Caregiver time loss & 829.09 & - & - & (38) \\
\hline Government benefits & 688.50 & - & - & (46) \\
\hline $\begin{array}{l}\text { a This includes acute otitis med } \\
\text { b Duration of illness (in years). } \\
{ }^{c} \text { Adjusted for regional differen } \\
\text { ( } 70 \% / 80 \% \text { ). } \\
\text { d Invasive pneumococcal disea } \\
\text { e The same efficacy rate for tub } \\
\text { f These treatment cost estimate }\end{array}$ & $\begin{array}{l}\text { is with hospital } \\
\text { ears (DALYs). } \\
\text { serotype distril } \\
\text { s or meningitis } \\
\text { d for adenoide } \\
\text { US (2006) dat }\end{array}$ & by multip & e publist & accine efficacy \\
\hline
\end{tabular}

program, S. pneumoniae was estimated to be responsible for 1236 pneumococcal meningitis cases and 364 pneumococcal sepsis cases in children under 5 years each year. An estimated 3122943 cases of AOM due to any cause; 315954 clinical pneumonia cases due to any cause; 196398 chest x-ray-confirmed pneumonia cases due to any cause also occurred annually in the same age group. Of the AOM and pneumonia cases, 320631 cases of AOM and 88961 cases of clinical

and chest $\mathrm{x}$-ray confirmed pneumonia were due to $S$. pneumoniae. Pneumococcal cases were associated with 71821 hospitalizations (21 per 1000 children) and 339370 outpatient visits (98 per 1000 children) annually.

Compared to no immunization, pneumococcal conjugate vaccination, if delivered at similar coverage rates as DTP3contained vaccines, would avoid an estimated 269136 cases of pneumococcal disease annually (80.8 cases of disease

TABLE 3. Annual projected health outcomes of pneumococcal conjugate vaccination in Brazil

\begin{tabular}{lrrrr}
\hline & No vaccine & With vaccination & Events averted & \% averted \\
\hline Acute otitis media $^{a}$ & 3122943 & 2913082 & 209862 & 7 \\
Clinical pneumonia $^{a}$ & 315954 & 306855 & 9099 & 3 \\
Chest x-ray confirmed pneumonia $^{a}$ & 196398 & 147271 & 49127 & 25 \\
Pneumococcal sepsis $^{\text {Pneumococcal meningitis }}$ & 364 & 126 & 238 & 65 \\
Deaths $^{b}$ & 20670 & 17369 & 809 & 65 \\
DALYs $^{c}$ & 697003 & 584829 & 112173 & 16 \\
\end{tabular}

\footnotetext{
a Due to any cause.

${ }^{b}$ Due to clinical pneumonia, chest x-ray confirmed pneumonia, pneumococcal sepsis, or pneumococcal meningitis.

${ }^{c}$ Disability-adjusted life years.
}

per 1000 children vaccinated), and avert 3301 deaths (0.99 life saved per 1000 children vaccinated) and 112173 DALYs annually. The largest number of cases prevented would be due to AOM, which was associated with 320631 health care visits. Pneumococcal pneumonia was associated with a large number of hospitalizations (70 221). The largest number of DALYs averted resulted from averted child deaths.

\section{Costs}

Overall, pneumococcal disease-associated outpatient visits and hospitalization incurred a cost of R\$34191203 (US\$ 17625 240) and R\$ 56606822 (US\$ 29180 278), respectively, amounting to an estimated total medical cost of $R \$ 26$ (US\$ 14) for each child born in Brazil by the age of 5. Most inpatient costs were attributed to hospitalization and the remainder to procedures and diagnostics. For outpatients, over half the costs was attributed to the cost of the visit. Direct non-medical cost associated with transportation was an additional $\mathrm{R} \$ 13.00$ (US\$ 7.00) for each child born in Brazil by 5 years of age.

An estimated 10.3 million doses of vaccine would be needed annually if current DTP3 rates were to be achieved for pneumococcal conjugate vaccine in Brazil. Total vaccine program costs, which include the cost for vaccine purchase at R\$ 51.12 (US\$ 26.35) per dose, would be approximately $\mathrm{R} \$ 527.9$ million (US\$ 272 million) per year for a threedose schedule. In our base case analysis, vaccination would avert $\mathrm{R} \$ 59.4$ million (US\$ 30.6 million) in direct medical costs per year. If non-medical costs and indirect costs were considered, vaccination would avert an additional R\$29.9 million (US\$ 15.4 million) annually. The undiscounted net cost (vaccine program costs minus averted disease costs) was R\$ 461 million (US\$ 238 million) annually. These net costs decreased as vaccine dose cost was reduced. At a lower vaccine price of R\$29.1 (US\$15) per dose, the net cost from the societal perspective was R\$ 242.3 million (US\$ 124.9 million) (Table 4).

\section{Cost-effectiveness}

Assuming a three-dose schedule and a health care perspective, pneumococcal vaccination, compared to no vaccination, 
TABLE 4. Annual projected cost-effectiveness of pneumococcal conjugate vaccination in Brazil

\begin{tabular}{|c|c|c|c|c|c|}
\hline \multirow[b]{2}{*}{ Dose cost $(\mathrm{R} \$)$} & \multirow[b]{2}{*}{$\begin{array}{c}\text { Vaccine cost } \\
(R \$)\end{array}$} & \multirow{2}{*}{$\begin{array}{c}\text { Net costs } \\
(\mathrm{R} \$)- \\
\text { societal } \\
\text { perspective }^{\mathrm{b}, \mathrm{c}}\end{array}$} & \multicolumn{2}{|c|}{$\mathrm{R} \$$ per $\mathrm{DALY} \mathrm{Y}^{\mathrm{a}}$ averted } & \multirow{2}{*}{$\begin{array}{l}\mathrm{R} \$ \text { per life } \\
\text { saved- } \\
\text { societal } \\
\text { perspective }\end{array}$} \\
\hline & & & $\begin{array}{c}\text { Healthcare } \\
\text { perspective }^{c}\end{array}$ & $\begin{array}{c}\text { Societal } \\
\text { perspective }^{d}\end{array}$ & \\
\hline \multicolumn{6}{|l|}{ 3-dose schedule } \\
\hline 51.12 & 527854805 & 461253992 & 4516 & 3946 & 135080 \\
\hline 38.8 & 400648880 & 342502284 & 3659 & 3128 & 106305 \\
\hline 29.1 & 300486606 & 242340082 & 2744 & 2213 & 75217 \\
\hline \multicolumn{6}{|l|}{ 4-dose schedule } \\
\hline 51.12 & 698130549 & 631529736 & 5973 & 5403 & 184946 \\
\hline 38.8 & 529890359 & 471743835 & 4839 & 4308 & 146618 \\
\hline 29.1 & 397417770 & 339271245 & 3629 & 3098 & 105302 \\
\hline
\end{tabular}

a Disability-adjusted life years.

b Undiscounted costs.

${ }^{c}$ Net costs is the total cost of the intervention minus the total cost of treating the illness that would occur in the absence of the intervention.

d Using discounted costs and health benefits. will cost between R\$2 744 (US\$ 1415$)$ and R\$ 4516 (US\$ 2328) per DALY averted in Brazil, as the cost per dose of vaccine ranges from $\mathrm{R} \$ 29.1$ (US\$ 15) to R\$ 51.12 (US\$26.35) (Table 4). When a societal perspective is considered, pneumococcal vaccination, compared to no vaccination, will cost between $\mathrm{R} \$ 2213$ (US\$ 1141 ) to R\$3 946 (US\$ 2 034) per DALY averted in Brazil, respectively. If the cost of administration of one dose of the vaccine is changed from $R \$ 0.00$ to $\mathrm{R} \$ 1.00$ (US\$ 0.52), the cost of pneumococcal vaccination will range from $\mathrm{R} \$ 4573$ (US\$ 2 357) per DALY averted (health care perspective) and R\$ 4042 (US\$2 084) per DALY averted (societal perspective) to R\$ 4605 (US\$ 2 374) per DALY averted (health care perspective) and $\mathrm{R} \$ 4035$ (US\$ 2080 ) per DALY averted (societal perspective), as the cost per dose of vaccine ranges from $\mathrm{R} \$ 29.1$ (US\$ 15) to R\$51.12 (US\$26.35).

Across all dose costs less than or equal to $\mathrm{R} \$ 51.12$ (US\$26.35), pneumococcal vaccination was projected to be very cost-effective, using WHO benchmarks (50) and a weighted average per capita GDP in Brazil of R 12436.72 (US\$ 6411 ) (35). The break-even cost per dose, that is, the cost per dose below which the vaccine became cost-saving, was R\$ 5.63 (US\$ 2.9) in the societal perspective analysis and less than $\mathrm{R} \$ 2$
TABLE 5. Annual projected cost-effectiveness of pneumococcal conjugate vaccination in Brazil using alternative cost scenarios ${ }^{\mathrm{a}}$

\begin{tabular}{|c|c|c|c|c|c|}
\hline \multirow[b]{2}{*}{ Dose cost $(\mathrm{R} \$)$} & \multirow[b]{2}{*}{$\begin{array}{c}\text { Vaccine } \\
\operatorname{cost}^{c}(R \$)\end{array}$} & \multirow{2}{*}{$\begin{array}{c}\text { Net costs } \\
(\mathrm{R} \$)- \\
\text { societal }^{\mathrm{d}, \mathrm{e}} \\
\text { perspective }^{\mathrm{d}, \mathrm{e}}\end{array}$} & \multicolumn{2}{|c|}{$\mathrm{R} \$$ per $\mathrm{DALY} \mathrm{Y}^{\mathrm{b}}$ averted } & \multirow{2}{*}{$\begin{array}{l}\mathrm{R} \$ \text { per life } \\
\text { saved- } \\
\text { societal } \\
\text { perspective }\end{array}$} \\
\hline & & & $\begin{array}{c}\text { Healthcare } \\
\text { perspective }^{d}\end{array}$ & $\begin{array}{c}\text { Societal } \\
\text { perspective }^{d}\end{array}$ & \\
\hline \multicolumn{6}{|c|}{ Scenario 1 (WHO-CHOICE $)^{f}$} \\
\hline 51.12 & 527854805 & 439523713 & 4820 & 4258 & 144726 \\
\hline 38.8 & 400648808 & 319619861 & 3783 & 3096 & 105244 \\
\hline 29.1 & 300486606 & 225207379 & 2990 & 2182 & 74156 \\
\hline \multicolumn{6}{|l|}{ Scenario $2(A M B)^{g}$} \\
\hline 51.12 & 527854805 & 461253992 & 4516 & 3946 & 135080 \\
\hline 38.8 & 400648808 & 257012130 & 3423 & 2347 & 79771 \\
\hline 29.1 & 300486606 & 156849928 & 2067 & 1432 & 48683 \\
\hline \multicolumn{6}{|c|}{ Scenario 3 (DATASUS + AMB) } \\
\hline 51.12 & 527854805 & 452610250 & 4820 & 4133 & 140480 \\
\hline 38.8 & 400648808 & 325404253 & 3644 & 2971 & 100998 \\
\hline 29.1 & 300486606 & 225242051 & 2759 & 2057 & 69910 \\
\hline
\end{tabular}

\footnotetext{
${ }^{a}$ Assumes a 3-dose schedule.

${ }^{\mathrm{b}}$ Disability-adjusted life years (DALYs).

c Undiscounted costs.

d Using discounted costs and health benefits.

${ }^{e}$ Net costs is the total cost of the intervention minus the total cost of treating the illness that would occur in the absence of the intervention.

${ }^{f}$ World Health Organization-Choosing Interventions that are Cost-Effective (WHO-CHOICE) project.

${ }^{g}$ Associação Médica Brasileira (AMB).
}

(US\$ 1.03) per dose in an analysis that considered health care system costs alone.

Table 5 shows the projected cost-effectiveness of pneumococcal conjugate vaccination in Brazil based on three separate cost scenarios (WHO-CHOICE, HMO/ $\mathrm{MCO}$, DATASUS + HMO/MCO). What is evident from this table is that the cost-effectiveness ratios ( $\mathrm{R} \$$ per DALY averted, R\$ per life saved) do not differ considerably from the cost-effectiveness ratios of the base case analysis, where only cost estimates from the public sector were considered. The same incidence data were used for the base case and secondary analyses. This caused the costeffectiveness ratios to vary some, particularly for scenario 2, where private costs were higher than the public costs used in the base case analysis. Another explanation for the similarities in the cost-effectiveness ratios is related to the costs themselves. These, although different, still accounted for the same cost components (direct medical, direct nonmedical, indirect costs) used in the base case analysis. Also, the same assumptions were made regarding the cost of transportation and lost productivity. This resulted in costs being consistent across scenarios. When the costs of treating sequelae due to AOM and pneumococcal meningitis were excluded from the analysis, changes in cost-effectiveness ratios were more evident in scenario 2 (HMO/MCO-private sector). Even these changes, however, did not have a significant impact on the cost-effectiveness ratios.

\section{Sensitivity analyses}

Sensitivity analyses were performed to assess the impact of specific variables on the cost-effectiveness ratios. We performed most sensitivity analyses using the PAHO vaccine price of $\mathrm{R} \$ 51.12$ (US\$ 26.35) per dose at a three-dose schedule. Incremental cost-effectiveness ratios were very sensitive to changes in estimates around vaccine dose costs (Figure 2). The point at which the line crosses the horizontal axis is the price at which the cost of vaccination (administration and vaccine itself) is offset by medical cost savings. At lower vaccine prices, vaccination would result in net medical cost savings for the particular group. Higher medical costs per child result in higher breakeven prices. 
FIGURE 2. Impact of changes in estimates around vaccine dose costs on cost-effectiveness ratios ${ }^{a}$

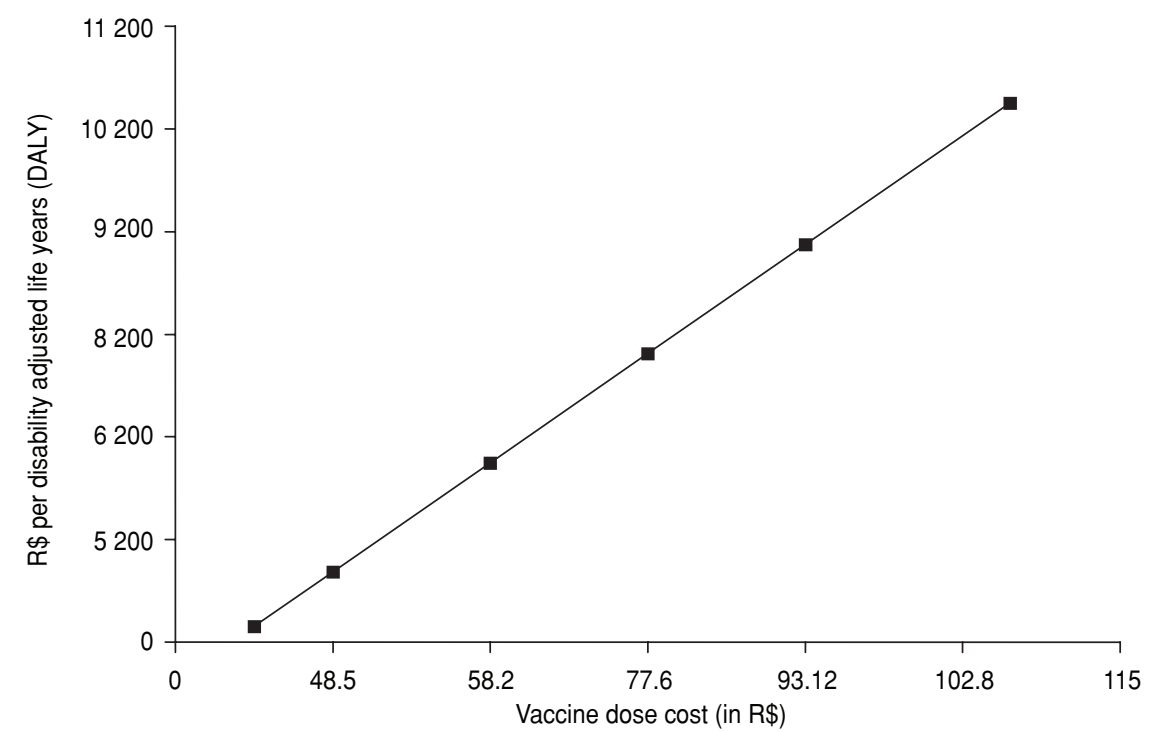

a Incremental cost-effectiveness ratios were sensitive to changes in estimates around vaccine dose costs. The point at which the line crosses the horizontal axis is the price at which the cost of vaccination (administration and vaccine itself) is offset by medical cost savings.

Other key variables affecting the costeffectiveness ratio were estimates of pneumonia-related vaccine efficacy. As the estimates of vaccine efficacy against clinical pneumonia and chest x-rayconfirmed pneumonia were varied simultaneously, the cost per DALY averted ranged from $\mathrm{R} \$ 1449$ (US\$ 747) to R\$ 4931 (US\$ 2 542) from the health care perspective.

The cost-effectiveness ratios were reduced when a $0 \%$ discount rate was used. In contrast, it became more expensive to prevent a DALY when a discount rate of $10 \%$ was assumed.

The large burden of pneumococcal otitis media is a significant contributor to the substantial health care system costs and broader use of antibiotics. Introduction of pneumococcal conjugate vaccines can greatly reduce the incidence of otitis media cases. However, pneumococcal otitis media does not result in significant childhood deaths in the region and, for this reason, incremental cost-effectiveness ratios are not sensitive to changes in estimates around otitis media cases.

In sensitivity analysis using scenarios 1 (WHO CHOICE) and 2 (HMO/MCO) for direct medical and nonmedical costs and indirect costs, the cost per DALY was R\$ 4258 (US\$ 2 195) and R\$ 3946 (US\$ 2 034), respectively (Table 5). The model was relatively insensitive to estimates of disease incidence across the plausible ranges considered.
After incorporating herd protection in the model, pneumococcal conjugate vaccination reduced the cost per DALY averted from R\$ 3946 (US\$ 2 034) to R\$ 1302 (US\$ 671) (societal perspective). If only treatment costs were included, the cost per DALY averted decreased from R\$ 4516 (US\$ 2328 ) to R\$ 1490 (US\$ 768). The cost per life saved was also reduced from $\mathrm{R} \$ 135,080$ (US\$ 69,632) to R $\$ 44,576$ (US\$ 22,979) (societal perspective). These estimates assumed a cost per dose of vaccine of $\mathrm{R} \$ 51.12$ (US\$ 26.35) and were based on U.S. invasive pneumococcal disease incidence data (43). It is estimated that pneumococcal conjugate vaccination would prevent 1.3 million cases of pneumococcal disease annually, and avert 7235 deaths annually if herd protection was incorporated.

\section{DISCUSSION}

The results of this analysis demonstrated that the incorporation of a heptavalent pneumococcal conjugate vaccine into the routine vaccination schedule in Brazil can effectively reduce the health and economic burden associated with $S$. pneumoniae. Under the base case scenario, vaccination reduced the medical costs associated with treating pneumococcal disease by $13 \%$, assuming vaccination occurs at the recommended time. An additional 269136 cases of pneumococcal dis- ease and 3301 pneumococcal deaths could be prevented annually in children under 5 years of age with the addition of this vaccine.

Across a wide range of vaccine costs per dose, pneumococcal conjugate vaccine would be a very cost-effective purchase in Brazil, based on WHO standards for evaluating the economic value of health interventions. At dose costs of R\$ 5.63 (US\$ 2.9), the vaccine would be cost-saving to Brazil, compared to no vaccination. These results are consistent with earlier analyses of vaccines for three Latin American countries (Brazil, Chile and Uruguay) that suggested that pneumococcal conjugate vaccine would have a cost-effective ratio of US\$ 664, US\$ 2 019, and US\$ 1546 per DALY averted, respectively (20). Another analysis of vaccines in low-income Global Alliance for Vaccines and Immunisation (GAVI)-eligible countries, which included six Latin American and Caribbean countries, suggested that at a vaccine cost of between US\$ 1.00 and US\$ 5.00 per dose, pneumococcal conjugate vaccine can be highly cost-effective (19).

The effectiveness of pneumococcal conjugate vaccination will depend, among other things, on the extent to which immunization programs reach the children at greatest risk of pneumococcal mortality. Many studies have identified a relationship between immunization status and mortality suggesting that infants who have been immunized are less likely to die than infants who are nonimmunized or incompletely immunized (51-54). It is unknown whether this association is only a result from poor access to care. A study in Pakistan demonstrated that only $40 \%$ of children who died from diarrhea or an acute respiratory infection were fully vaccinated versus a coverage level of $91 \%$ in children who suffered from diarrhea or respiratory infection but did not die (55). If those who die are less likely to be vaccinated, the effectiveness (and cost-effectiveness) of vaccination will be reduced. In the present analysis a 50\% reduction in coverage, from an estimated relative coverage of $96 \%$ to $48 \%$ would result in almost 1651 fewer deaths prevented in an annual birth cohort assuming on-time vaccination. Targeted efforts to increase the coverage of children at the greatest risk could improve the impact of vaccination on pneumococcal mortality, as seen in the Gambian study (56). 
In addition, the cost-effectiveness of vaccination depends largely on vaccine price, which is currently unknown, and the cost-effectiveness standard used. Health interventions that result in negative net costs are excellent investments since they result in improved health and cost-savings; however, few interventions (even highly effective ones such as vaccines) meet this standard.

Decisions regarding the introduction of pneumococcal conjugate vaccine in Brazil are likely to be made in the near future. Newer and more expensive vaccines (e.g., Haemophilus influenzae type B, hepatitis B) have traditionally been slow to reach national immunization programs in countries like Brazil, due in part to their cost (57). Despite these difficulties, in 2006 Brazil became the first country in the world to introduce the rotavirus vaccine into the routine immunization program at the price of US $\$ 8.00$ per dose (personal communication, Dr. Luiza Helena Falleiros Carvalho, Programa Nacional de Imunizações, Ministério da Saúde de São Paulo, December 2006).

The analysis presented here identified important uncertainties that are likely to affect our estimate of vaccine benefit. For example, the mortality reduction benefit of vaccination will depend on the programmatic issues related to the ability of vaccination to reach children in a timely manner. In particular, delays in the timing of vaccination can result in children being vaccinated after the peak age period for pneumococcal disease hospitalization and mortality. The effect is most noticeable in the north of Brazil where mortality and delays in vaccination are greatest. Similarly, increasing overall coverage rates would also increase the number of preventable deaths.

Our base case analysis was conservative in that it did not consider the potential indirect protective effect of herd immunity for persons unprotected by the vaccine. Because of paucity of data, herd protection effects were only incorporated in the sensitivity analysis using invasive pneumococcal disease incidence data from the United States (44). Results of the sensitivity analysis are in accord with earlier cost-effectiveness analyses showing that ICERs are significantly reduced when herd immunity effects are considered $(43,52)$.

While according to a threshold of the country's GDP per capita pneumococcal conjugate vaccination would be very costeffective in Brazil, it is unclear whether the vaccine will be affordable. This paper deals with issues related to value for money and opportunity costs of not investing the dollars elsewhere. The paper does not deal with issues of affordability, which is about impact on the current budget and financial costs over a shorter-time horizon. Future studies should focus on the cost to vaccinate a single birth cohort at different coverage rates.

Limitations of this analysis include, but are not limited to, uncertainties around the efficacy of the vaccine with 2 +1 schedules, gaps in our understanding of herd protection with $2+1$ schedules, uncertainties around the epidemiology of pneumococcal disease, and costs associated with pneumococcal disease. We provided some estimates of herd protection derived from the U.S. experience $(3+$ 1 schedule). However, initial studies in countries with $2+1$ schedules have consistently failed to observe herd protection. Maybe we will have more data in the near future, but so far the evidence is limited to the $3+1$ schedule. In addition, the base case estimate for otitis media is extrapolated from a study from Boston. It is unclear how this estimate compares to what happens in Brazil.

We used vaccine efficacy data from the Kaiser Permanente clinical trial of the heptavalent pneumococcal conjugate vaccination. Although we adjusted for key variables influencing the costeffectiveness ratio (that is, vaccine coverage, serotype coverage, age at vaccination, and disease burden), the vaccine efficacy data may be relevant only to the specific setting and timeframe of the trial. Because this trial was conducted in the United States, the vaccine efficacy data may not be generalizable to Brazil. Nonetheless, studies of heptavalent pneumococcal conjugate vaccine among Native Americans and nonavalent pneumococcal conjugate vaccine in Africa also showed high efficacy.

We assumed that all children were fully vaccinated at levels of coverage with three doses of DTP vaccine and did not adjust for potential protection provided by incomplete vaccination (e.g., receiving only one or two doses of the heptavalent pneumococcal conjugate vaccine). Such protective effects would have increased vaccine cost-effectiveness.

Our vaccine coverage estimate was based on coverage of the third dose of
DTP. We assumed that all groups within Brazil would have equal likelihood of vaccination and would be vaccinated at the recommended time. If high-risk populations are missed or vaccination is delayed, the effectiveness may be reduced.

Brazil has introduced childhood pneumococcal conjugate vaccination for high risk groups. However, this strategy is not included in the current analysis because the original plan of this analysis was to support the Brazilian Ministry of Health in the decision of introducing the universal pneumococcal conjugate vaccination in infants in Brazil. Clearly, the incremental benefits of introducing the pneumococcal conjugate vaccine into the general child population will be greatly altered if the high-risk strategy is incorporated into the model as well.

In the current analysis, unadjusted charge data were used and the assumption was made that these data were based on actual resource costs. This a potential bias in the analysis as charges for medical services are greater than the actual cost of resource inputs. The social opportunity cost is presumed to be less than the price charged as the potential alternative output relates to the resources used rather than the charges levied.

Due to methodological difficulties and time constraints, we did not consider the potential indirect protective effect of herd immunity on people who are not vaccinated. Herd immunity could offset gaps in delivery of full course, on-time vaccination, as well as prevent disease in non-targeted populations, and improve the cost-effectiveness of a heptavalent pneumococcal conjugate vaccination program.

\section{Conclusion}

This paper assesses the cost-effectiveness of a pneumococcal conjugate vaccination program in Brazil, compared with no vaccination. Pneumococcal disease causes a significant health and economic burden in Brazil. The results presented here demonstrate that pneumococcal conjugate vaccination could greatly reduce the disease burden and mortality if incorporated into the national immunization schedule and, when compared to WHO benchmarks for cost-effectiveness, pneumococcal conjugate vaccine could be cost-effective compared to other options to control childhood dis- 
eases. It is unclear, however, whether this vaccine is affordable when weighed against competing priorities. More work on the cost-effectiveness of pneumococcal conjugate vaccination programs needs to be done in Brazil and other countries of the region, where there is currently dire paucity of literature in the economics of vaccines. The critical areas should include the development of dif- ferent evaluation methods in different settings. Another would be the ascertainment of the best ways to present costeffectiveness results in local contexts. In addition, the reliability and validity of estimates should be determined.

Acknowledgments. The authors would like to thank Luiza Helena Falleiros Carvalho, Otávio Cintra, José Geraldo Leite
Ribeiro and Gabriel Oselka for their valuable input in reviewing the study protocol and making suggestions. Funding for the study was provided by Wyeth Industria Farmacêutica, São Paulo, Brazil. The funding source had no role in the design and conduct of the study; collection, management, analysis, and interpretation of the data; or preparation, review, or approval of the manuscript.

\section{REFERENCES}

1. World Health Organization (WHO). Report of a meeting on priorities for pneumococcal and Haemophilus influenzae type b (Hib) vaccine development and introduction. Geneva, February 9-12, 1999. WHO/V\&B/01.14. Available from: http://www.who.int/vac cines-documents/DoxGen/H4-Inno.htm. Accessed October 52009.

2. Black $S$, Shinefield $H$, Fireman B, Lewis E, Ray P, Hansen JR, et al. Efficacy, safety and immunogenicity of heptavalent pneumococcal conjugate vaccine in children. Northern California Kaiser Permanente Vaccine Study Center Group. Pediatr Inf Dis J. 2000;19(3): 187-95.

3. Black SB, Shinefield HR, Ling S, Hansen J, Fireman B, Spring D, et al. Effectiveness of heptavalent pneumococcal conjugate vaccine in children younger than five years of age for prevention of pneumonia. Pediatr Inf Dis J. 2002;21:810-5.

4. Fireman B, Black SB, Shinefield HR, Lee J, Lewis E, Ray P. Impact of the pneumococcal conjugate vaccine on otitis media. Pediatr Infect Dis J. 2003;22(1):10-6.

5. Hansen J, Black S, Shinefield H, Cherian T, Benson J, Fireman B, et al. Effectiveness of heptavalent pneumococcal conjugate vaccine in children younger than 5 years of age for prevention of pneumonia: updated analysis using World Health Organization standardized interpretation of chest radiographs. Pediatr Infect Dis J. 2006;25(9):779-81.

6. World Health Organization (WHO). Pneumococcal Conjugate Vaccine for Childhood Immunization-WHO position paper. Wkly Epidemiol Rec. 2007;82(12):93-104.

7. United Nations Development Programme (UNDP). Investing in development-A practical guide to achieve the Millennium Development Goals. 2005. Available from: www. unmillenniumproject.org/reports / full report.htm. Accessed 10 December 2007.

8. Butler JR, McIntyre P, MacIntyre CR, Gilmour $R$, Howarth AL, Sander B. The cost-effectiveness of pneumococcal conjugate vaccination in Australia. Vaccine. 2004;22(9-10):1138-49.

9. D'Alessandro D. [Costs of pneumococcal infections and cost evaluation of heptavalent conjugate vaccine]. Ann Ig. 2002;14(6 Suppl 7):43-8.

10. De Wals P, Petit G, Erickson LJ, Guay M, Tam $\mathrm{T}$, Law B, et al. Benefits and costs of immunization of children with pneumococcal conjugate vaccine in Canada. Vaccine. 2003;21 (25-26):3757-64.
11. Ess SM, Schaad UB, Gervaix A, Pinosch S, Szucs TD. Cost-effectiveness of a pneumococcal conjugate immunization program for infants in Switzerland. Vaccine. 2003;21(23): 3273-81.

12. Hueston WJ, Mainous AG 3rd, Brauer N. Predicting cost-benefits before programs are started: looking at conjugate vaccine for invasive pneumococcal infections. J Community Health. 2000;25(1):23-33.

13. Jacobs RJ, Meyerhoff AS. Comparative cost effectiveness of varicella, hepatitis A, and pneumococcal conjugate vaccines. Prev Med. 2001;33(6):639-45.

14. Lebel MH, Kellner JD, Ford-Jones L, Hvidsten K, Wang EC, Ciuryla V, et al. A pharmacoeconomic evaluation of 7-valent pneumococcal conjugate vaccine in Canada. Clin Infect Dis. 2003;36(3):259-68.

15. Lieu TA, Ray GT, Black SB, Butler JC, Klein JO, Breiman RF, et al. Projected cost-effectiveness of pneumococcal conjugate vaccination of healthy infants and young children. JAMA. 2000;283(11):1460-8.

16. McIntosh ED. Cost-effectiveness studies of pneumococcal conjugate vaccines. Expert Rev Vaccines. 2004;3(4):433-42.

17. McIntosh ED, Conway P, Willingham J, Lloyd A. The cost-burden of paediatric pneumococcal disease in the UK and the potential cost-effectiveness of prevention using 7 valent pneumococcal conjugate vaccine. Vaccine. 2003;21(19-20):2564-72.

18. Melegaro A, Edmunds WJ. Cost-effectiveness analysis of pneumococcal conjugate vaccination in England and Wales. Vaccine. 2004; 22(31-32):4203-14.

19. Sinha A, Levine O, Knoll MD, Muhib F, Lieu TA. Cost-effectiveness of pneumococcal conjugate vaccination in the prevention of child mortality: an international economic analysis. Lancet. 2007;369(9559):389-96.

20. Constenla D. Economic impact of pneumococcal conjugate vaccination in Brazil, Chile, and Uruguay. Rev Panam Salud Publica. 2008;24(2):101-12.

21. Brazil, Ministério da Saúde. DATASUS 2003 (based on 2002 census data). Brasília: Ministério da Saúde. Available from: wwwdata sus.gov.br. Accessed 19 May 2007.

22. Gold MR, Siegel JE, Russell LB and Weinstein MC. Cost-effectiveness in health and medicine. New York: Oxford University; 1996.

23. Murray CJL, Lopez AD. The global burden of disease. Geneva: World Health Organization;
1996. (Global Burden of Disease and Injury Series).

24. Andrade AL, Silva SA, Martelli CM, Oliveira RM, Morais Neto OL, Siqueira Junior JB, et al. Population-based surveillance of pediatric pneumonia: use of spatial analysis in an urban area of Central Brazil. Cad Saude Publica. 2004;20(2):411-21.

25. Teele DW, Klein JO, Rosner B. Epidemiology of otitis media during the first seven years of life in children in greater Boston: a prospective, cohort study. J Infect Dis. 1989;160(1): 83-94.

26. Sistema Nacional de Agravos de Notificação (SINAN). Available from: www.datasus. gov.br/. Accessed 14 March 2007.

27. Constenla D. Evaluating the costs of pneumococcal disease in selected Latin American countries. Rev Panam Salud Publica. 2007: 22(4);268-78.

28. Szklo M, Nieto FJ. Epidemiology: beyond the basics. Gaithersburg: Aspen; 2000.

29. de Andrade AL, de Andrade JG, Martelli MT, Silva SA, de Oliveira RM, Costa MS, et al. Effectiveness of Haemophilus influenzae b conjugate vaccine on childhood pneumonia: a case-control study in Brazil. Int J Epidemiol. 2004;33(1):173-81.

30. Rudan I, Tomaskovic L, Boschi-Pinto C, Campbell H; WHO Child Health Epidemiology Reference Group. Global estimate of the incidence of clinical pneumonia among children under five years of age. Bull World Health Organ. 2004;82(12):895-903.

31. Brandileone MC, Casagrande ST, Guerra ML, Zanella RC, Andrade AL, di Fabio JL. Increase in numbers of $\beta$-lactam-resistant invasive Streptococcus pneumoniae in Brazil and the impact of conjugate vaccine coverage. J Med Microbiol. 2006;55(Pt 5):567-74.

32. Terra de Souza AC, Cufino E, Peterson KE, Gardner J, Vasconcelos do Amaral MI, Ascherio A. Variations in infant mortality rates among municipalities in the state of Ceará, Northeast Brazil: an ecological analysis. Int J Epidemiol. 1999;28(2):267-75.

33. Valenzuela MT, O'Loughlin R, de la Hoz FP, Gomez E, Constenla D, Sinha A, Valencia JE, Flanner B, de Quadros C for the Technical Advisory Group. The burden of pneumococcal disease among Latin America and the Caribbean children: a review of the evidence. Pan Am J Public Health. 2009:25(3):270-79.

34. Pan-American Health Organization. Health situation in the Americas: basic indicators. Washington: PAHO/WHO; 2005. 
35. Brazil, Ministério da Fazenda. Banco Central do Brasil, 2006. Available from: www.bcb. gov.br/. Accessed 14 July 2007.

36. Brazil, Ministério da Saúde. DATASUS 2006. Brasília: Ministério da Saúde. Available from: www.tabnet.datasus.gov.br/cgi/idb2006/m atriz.htm. Accessed 14 July 2007.

37. Associação Nacional das Empresas de Transportes Urbanos-NTU, 2007. Available from: www.ntu.org.br/novosite/. Accessed 14 July 2007.

38. Fundação Getulio Vargas (FGV). Rev Conjuntura Economica. 2006;61(2):VIII. Available from: www.fgv.br/. Accessed 14 July 2007.

39. Governo do Estado de São Paulo, Secretaria de Assistência e Desenvolvimiento Social. Available from: www.desenvolvimentoso cial.sp.gov.br. Accessed 14 July 2007.

40. World Health Organization (WHO). WHOChoosing interventions that are cost-effective (WHO-CHOICE). Prices for hospitals and health centres. Available from: www.who. int/choice/costs/en/. Accessed 20 January 2004.

41. Associação Médica Brasileira (AMB) data 2006. Available from: www.datasus.gov.br/. Accessed 14 July 2007.

42. Carvalho DM. Grandes sistemas nacionais de informação em saúde: Revisão e discussão da situação atual. Informe Epidemiol SUS. 1997;5(4):7-46.

43. Ray GT, Whitney CG, Fireman BH, Ciuryla V, Black SB. Cost-effectiveness of pneumococcal conjugate vaccine-Evidence from the first 5 years of use in the United States incorporat- ing herd effects. Pediatr Infect Dis J. 2006; 25(6):494-501.

44. Sistema de Informações Ambulatoriais (SIA/ SUS), DATASUS 2006. Available from: http:// www.datasus.gov.br/. Accessed 14 March 2007.

45. Sistema de Informação Hospitalar (SIH/ SUS), DATASUS 2006. Available from: http:// www.datasus.gov.br/. Accessed 14 March 2007.

46. Brazil, Ministério do Planejamento. Instituto de Pesquisa Econômica Aplicada (IPEA), 2006. Available from: http://www.ipea.gov. br/default.jsp. Accessed 14 July 2007.

47. Fox-Rushby JA, Hanson K. Calculating and presenting disability-adjusted life years (DALYs) in cost-effectiveness analysis. Health Policy Plan. 2001;16(3):326-31.

48. Brazil, Ministério da Saúde. DATASUS, 2004. Available from: www.tabnet.datasus.gov. br/cgi/idb2004/matriz.htm. Accessed 14 March 2007.

49. Drummond MF, O'Brien B, Stoddart GL, Torrance GW. Methods for the economic evaluation of health care programmes. 2nd ed. Oxford: Oxford University; 2000.

50. World Health Organization. World Health Report 2002: Reducing risks, promoting healthy life. Available from: http://www. who.int/whr/2002/en/whr02_en.pdf. Accessed October 2009.

51. Hirve S, Ganatra B. A prospective cohort study on the survival experience of underfive children in rural western India. Indian Pediatr. 1997;34(11):995-1001.
52. McIntosh ED, Conway P, Willingham J, Hollingsworth R, Lloyd A. Pneumococcal pneumonia in the UK-how herd immunity affects the cost-effectiveness of 7-valent pneumococcal conjugate vaccine (PCV). Vaccine. 2005;23(14):1739-45.

53. Wang L. Determinants of child mortality in LDCs: empirical findings from demographic and health surveys. Health Policy. 2003;65(3): 277-99.

54. Suwal JV. The main determinants of infant mortality in Nepal. Soc Sci Med. 2001;53(12): 1667-81.

55. D'Souza RM, Bryant JH. Determinants of childhood mortality in slums of Karachi, Pak istan. J Health Popul Dev Ctries. 1999;2(1): 33-44.

56. Cutts FT, Zaman SM, Enwere G, Jaffar S, Levine OS, Okoko JB, et al. Efficacy of nine-valent pneumococcal conjugate vaccine against pneumonia and invasive pneumococcal disease in The Gambia: Randomised, doubleblind, placebo-controlled trial. Lancet. 2005; 365(9465):1139-46.

57. Lieu TA, McGuire TG, Hinman AR. Overcoming economic barriers to the optimal use of vaccines. Health Aff (Millwood). 2005 24(3):666-79

Manuscript received on 25 August 2008. Revised version accepted for publication on 20 January 2009.

RESUMEN Objetivo. Comparar los costos y los beneficios de la aplicación de la vacuna conjugada antineumocócica en comparación con la no vacunación, desde las perspectivas del sistema de salud y la sociedad.

Cálculo de la relación costo-efectividad de la vacuna conjugada antineumocócica en Brasil

Palabras clave
Métodos. A partir de fuentes reconocidas, se estimaron la incidencia y la mortalidad por enfermedad neumocócica invasora, neumonía y otitis media aguda (OMA) para una cohorte hipotética de niños desde su nacimiento hasta los 5 años.

Resultados. Se estimó que un programa de vacunación universal con una vacuna conjugada antineumocócica sería capaz de evitar anualmente 1047 casos de la enfermedad invasora, 58226 casos de neumonía y 209862 casos de OMA. Si se considera el efecto de la inmunidad de grupo, el programa evitaría 1,3 millones de casos de enfermedad y más de 7000 muertes por infección neumocócica. A R\$ 51,12 (US\$ 26,35) por dosis, la vacunación costaría anualmente R\$ 4286 (US\$2,211) por cada año de vida ajustado por discapacidad evitado, sin tomar en cuenta el efecto de la inmunidad de grupo.

Conclusiones. En comparación con otras opciones de control de estas enfermedades infantiles y con los precios actuales de la vacuna conjugada, la vacunación antineumocócica podría ser una inversión efectiva en función del costo. Se requieren más estudios para determinar si la vacunación es costeable para Brasil a los precios actuales.

Streptococcus pneumoniae; infecciones neumocócicas; vacunas neumococicas; análisis costo-eficiencia; Brasil. 